\title{
3 November 2014
}

Practical Appraisal Techniques for Valuing Adaptive Capacity in Flood and Coastal Erosion Risk Management

\section{Authors}

Rachel Brisley, BA, Dip TRP, MCD, MBA. Technical Director - JBA Consulting

Richard Wylde, MMet. Scientist - JBA Consulting

Prof Rob Lamb, BA, MA, PhD. Director - JBA Trust. Honorary Professor, Lancaster Environment Centre Jonathan Cooper, BEng, MSc, DipCD, CEng, MICE, MCIWEM, C.WEM, MloD. Director - JBA Consulting Eur Ing Paul Sayers, BEng, CEng, MICE. Partner, Sayers and Partners, Visiting Fellow - University of Oxford.

Prof Jim Hall, BEng MA PhD FREng FICE. University of Oxford

\section{Submitting author}

Rachel Brisley, JBA Consulting, Bank Quay House, Sankey Street, Warrington, WA1 1NN

Tel: 01925570876 or 07436545359

Email: $\underline{\text { rachel.brisley@jbaconsulting.com }}$

\section{Contents}

Number of words: 4,888

Number of figures: 3

\section{Figures}

Figure A: Fit with FCERM plan and project appraisal guidance

Figure B: Case study example map

Figure C: Case Study Decision Tree

\section{Tables}

Table A. Autonomous futures used as change scenarios in example decision tree analysis Table B Performance analysis for decision pathways in Figure D

Table C Opportunity loss (regret) table, $\mathrm{fm}$ 


\begin{abstract}
Flood and coastal erosion risk management has always faced the challenge of decision-making in the face of multiple uncertainties relating to the climate, the economy and society. Traditionally, this has been addressed by adopting a precautionary approach which seeks to protect against a reasonable worst case. However, a managed adaptive approach can offer advantages. The benefits include improved resilience to negative changes, enabling opportunities from positive changes and greater cost-effectiveness. The absence of clear methods and tools to value adaptive approaches has been recognised as an obstacle to wider adoption. In this paper a staged approach to building in adaptive capacity is proposed, which systematically analyses uncertainties, identifies opportunities to incorporate adaptability, and appraises benefits through the analysis of decision trees. A case study is presented. The methodology is set in the context of appraisal processes used in England by the Environment Agency, based on HM Treasury's costbenefit analysis guidance. The approach is transferable to other situations worldwide, where decisionmaking is based on quantified assessment of costs and benefits. The work should help decision-makers to fully appraise the benefits of building in adaptive capacity and make the economic and technical case for adaptive flood risk management in an uncertain environment.
\end{abstract}

Three key words (ICE journals): Floods \& flood works, Economics \& finance, Risk \& probability analysis 


\section{Introduction}

There are many sources of uncertainty and drivers of future change that communities and decisionmakers could be better prepared for by adopting more adaptable plans to manage flood and erosion risks. It may not be possible to reduce uncertainty, at least in the short term, but recognising and accepting uncertainty and being better able to manage it can save money and help to reduce risk.

The capacity of organisations, institutions and individuals to adapt to changes in their wider environment varies considerably between and within sectors. This paper focuses upon improving the adaptive capacity of the flood and coastal erosion risk management (FCERM) industry in England (although the generic approaches are applicable elsewhere) through the development of practical approaches to support the appraisal of managed adaptive approaches. The characteristic time-scales for investments in FCERM are of the order of 10 to 100 years. Over these timescale, uncertainties surrounding climatic and socio-economic changes can have a significant influence on the benefits that investment in FCERM can be expected to accrue. In fact, the uncertainties may be so great that it is hard to make the case for major investments now, other than by adopting a 'precautionary' approach, which may incur excessive costs. This paper explains how the adoption of adaptive approaches, which build in flexibility, can help stakeholders react to future uncertainties as they materialise during the life of a project, which may prove to be more cost-effective over the long term.

The managed adaptive approach to FCERM promotes an holistic and long-term approach which reinforces existing climate change policy by promoting actions that also support other socio-economic objectives and longer term adaptability. The approach advocates flexibility and adaptability in responses.

The adaptive approach differs from the more traditional approach to FCERM - the precautionary approach - in which assumptions are made of what might happen in the future and a fixed investment programme is planned accordingly.

Managed adaptive and precautionary approaches are not mutually exclusive; to a large degree, the adaptive approach is precautionary in that it ensures options are open for future change rather than applying locked-down solutions. 
Accepting and managing uncertainty is not easy and, while there are few arguments against the benefits of managed adaptive approaches, there can be difficulties with their justification, development, valuation and implementation. Previous research (Defra 2009b) identified specific barriers to the development and appraisal of adaptive approaches, which largely relate to the mind-sets and skills of decision-makers at national and local levels:

- a lack of systems thinking involving narrow problem definition

a focus on the status quo; risk and uncertainty aversion

$\bigcirc$ an inability to value the benefits of adaptation and the costs of not adapting

- a lack of evidence explicitly identifying examples of adaptive approaches or evidencing their efficiency, effectiveness and general improved performance.

In addition, whilst there is policy support for adaptive approaches and guidance is available for their appraisal, limited explanation is provided for how practitioners and decision-makers should develop and gain support for adaptive approaches and how these should then be appraised.

Despite the above constraints, the current political, institutional and technical context should encourage adaptive approaches in terms of advances made in the underlying methods for analysing uncertainties in FCERM; improvements in understanding future climate uncertainties; increasing demand from stakeholders for methods and tools that can demonstrate the value of building future adaptability into FCERM; and institutional capacity building particularly within lead local flood authorities (LLFAs).

\section{The appraisal policy context in England}

Decision-making for public sector investment in FCERM in England is informed by detailed appraisal using the Environment Agency's FCERM appraisal guidance - FCERM-AG (2010a) which in turn is based on the requirements of HM Treasury's Green Book (2003). In essence, this requires the definition of the problem; identification of possible options to address the problem; comparison of options in relation to value for money, technical, environmental and social viability; selection of a preferred option; and ongoing monitoring and feedback. The adaptive approach is promoted in supporting documents to existing appraisal guidance including supplementary guidance to the Green Book on accounting for the 
effects of climate change, produced by HM Treasury and the Department for Environment, Food and Rural Affairs (Defra - 2009) and the Environment Agency's advice on adapting to climate change (Environment Agency 2010c).

\section{Methodology}

This paper reports on a project which aimed to establish best practice for incorporating adaptive capacity in appraisal decisions. The project was undertaken over 18 months (2012/13) via four stages:

- Stage 1: Market analysis - investigation of the types of responses required to improve on the current situation and support culture change on adaptive thinking within the appraisal process.

- Stage 2: Gap analysis - extension of Stage 1 to identify gaps and suggest potential methods for promoting and appraising managed adaptive approaches to FCERM in a range of decision contexts.

- Stage 3: Development and testing - development of tools and guidance, piloting these through case studies and presenting the revised approaches at a stakeholder workshop.

- Stage 4: Review and finalisation - refinement of the resulting tools and guidance following market testing by stakeholders and practitioners.

As the aim was to provide guidance that should help improve the adaptive capacity of the FCERM industry, stakeholder consultation throughout was of crucial importance. A Project Board oversaw the project and was involved from project commencement to completion. The Project Board members comprised representatives from the Environment Agency, Natural Resources Wales and Defra. A wider Project Steering Group, which acted as a sounding board, consisted of representatives from: the Environment Agency, Defra, Welsh Government, London School of Economics, LLFAs, Internal Drainage Boards and consultants.

The key aspects of consultation and market review comprised:

- Two stakeholder workshops (early market analysis and consideration of draft outputs towards the end of the study), which involved presentation of the key issues/draft outputs and then break-out groups to discuss issues concerning the take up of adaptive approaches and the reality of using the draft tools. These were attended by the Project Board, Project Steering 
Group and additional interested FCERM practitioners and decision-makers from the

Environment Agency, LLFAs, Welsh Government and consultants.

- Consultation on two draft interim reports with the Project Board; these were discussed via Live Meetings and comments provided by email.

- Market testing of the final outputs with the Project Board, Project Steering Group and wider FCERM decision-makers and practitioners. This involved trialling of the tools to assess their potential use, user-friendliness and likelihood of future adoption.

The outcomes from the various elements of consultation informed the development of the project outputs and are detailed within this paper as the outputs are described.

The overall objectives for the study, which were refined following the initial market testing workshop, were to:

- Help inspire adaptive thinking in developing FCERM responses.

- Provide supporting methods and tools for decision support and valuation, in particular matching specific methods for evaluating adaptive capacity to particular stages in the appraisal process.

- Present worked examples to illustrate the concepts set out in the Green Book supplementary guidance.

- Target both non-technical decision-makers and experienced FCERM practitioners.

\section{Appraisal Framework}

\section{Overall purpose}

The main project output was the development of a supplementary appraisal guide providing practical tools and approaches that can help promote and appraise managed adaptive approaches in FCERM. It supplements existing guidance rather than presenting a new approach and should help with the 'How do I do it?' question which is lacking in current guidance. The advice within the guide was developed with the intention of ensuring that its application is proportionate and relevant to the problem or opportunity that is being addressed. 
The guide was intended to encourage and promote principles that characterise managed adaptive approaches. These principles, developed with input from the Project Board, are that FCERM should be:

- Sustainable - building in flexibility and ensuring that investments can be adapted to future circumstances is a very practical way of achieving sustainability.

- Flexible - avoiding 'locked-in' responses, which cannot be readily adapted in the long term and can result in significant sunk costs.

- Resilient - building in measures that will continue to function and promote recovery when exposed to either extreme events that exceed design conditions or unforeseen future change.

- Favour no regrets, low regrets and win-win measures - providing benefits that satisfy multiple objectives will gain greater support from stakeholders than single-issue solutions which could be costly and only reap the benefits in limited alternative futures.

- Promote whole system thinking and collaboration - focusing on addressing the linkages between multiple agendas (economic/environmental/social) under a range of future uncertainties.

\section{Guide content \& links to existing published guidance}

Stakeholders and practitioners also considered that the guide should align with existing appraisal approaches as far as possible rather than providing a totally new methodology and be established as a non-prescriptive road map populated with examples. This resulted in the guide being framed as supplementary to, but clearly aligning with, the different stages of FCERM appraisal. 
Figure A shows how the different elements of the guide fit with existing appraisal guidance:

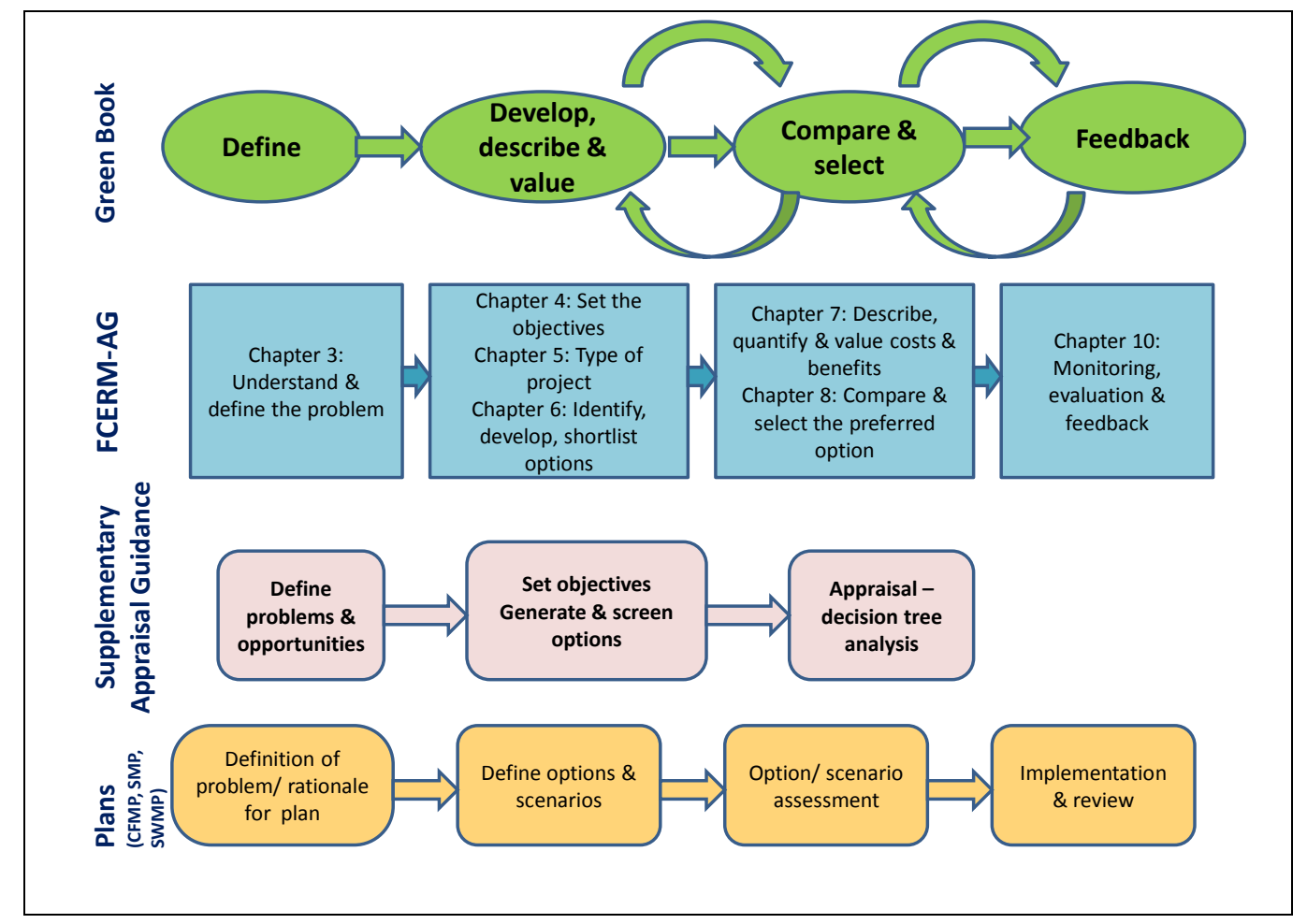

Figure A: Fit with FCERM plan and project appraisal guidance

\section{Summary of early stages - Building Adaptive Capacity \& Developing Managed Adaptive}

\section{Approaches}

\section{Building Adaptive Capacity}

The guide specifies that the appraisal process should commence with an assessment of the benefits of a managed adaptive approach against criteria such as the extent of competing interests and the significance of future uncertainty in decision making as such approaches will not be appropriate in all situations. Where they are appropriate and progressed, the criteria can be used to capture adaptability in the appraisal. Two specific tasks follow from this:

- Define problems and opportunities - this requires the collation and understanding of evidence on the drivers of future change such as population growth, climate change and economic development, and then assessment of the potential impacts and opportunities should these changes be realised. This task also introduces the concept of decision trees as an effective approach for considering future uncertainty. 
- Set objectives - the way in which objectives are set fundamentally influences the way that plans and projects are developed and implemented. The guide provides advice on how to set objectives that promote long-term sustainability, adaptation and resilience.

Whilst these tasks do not in themselves revolve around radically new ideas, the guide is novel in attempting to codify these tasks in some detail within the formal appraisal process for FCERM investments and plans.

\section{Developing Managed Adaptive Approaches}

A key motivation for the development of additional guidance was the limited adoption of managed adaptive approaches, in part due to the FCERM industry having difficulties in visualising exactly what these are and how they operate. The advice concerning the generation of options identifies attractive attributes of adaptive responses, which should help ensure that the associated option is resilient to future change or capable of modification. Terminology is important in that the option consists of a package of measures: individually these do not have to be adaptive, but the overall process in which they are implemented does. This was specifically highlighted by stakeholders at the market testing workshop. The attractive attributes support current FCERM policy objectives in relation to reducing vulnerability and making space for water, but also specifically highlight the need to build in future flexibility.

Once adaptive options have been generated, there is a need to screen out options on the basis of potential adaptability as well as more conventional assessments of feasibility (financial, technical, environmental and social viability). Stakeholders recommended that the defined attractive attributes should be used in option screening as well as option generation and also supported the premise that the screening approach should not be used to knock out options or select the 'best' one; its intent is discussion not decision-making.

The guide also presents a quantitative multi-criteria decision analysis (MCDA) approach in which attributes specifically designed to capture flexibility can be considered alongside the more conventional attributes assessed at appraisal concerning technical, financial and environmental viability. MCDA outputs can be a useful approach to aid discussion, particularly where results are presented graphically. 


\section{Valuing managed adaptive approaches}

\section{Introduction}

The purpose of option appraisal is to enable the previously shortlisted options to be evaluated in more detail, eventually leading to the selection of the preferred option for investment. The appraisal is undertaken within the Green Book framework, which requires the best estimate of costs and benefits for each option. A crucial element of appraisal is adjusting for the timing of the incidence of costs and benefits by discounting them, to obtain their present values presented as the Net Present Value (NPV) or Benefit Cost Ratio (BCR) of each option. Here, the term "option" is used in the sense of a decision about possible courses of action to be made now or in the near term.

Existing guidance in FCERM-AG recommends considering the performance of options under alternative possible future scenarios with a view to ensuring a robust decision is reached. The FCERM-AG makes some recommendations about sensitivity testing, but does not incorporate state of the art research about robust decision-making approaches. However, full evaluation of an adaptive approach requires additional steps in the appraisal, which consider not only the initial options, but also the merits of further decisions at certain points in time that allow a greater or lesser degree of adaptability. Incorporating future optionality can greatly increase the complexity of the decision problem. Drawing on research from the fields of finance, economics and operations research, and in particular Real Options analysis (Dixit and Pindyck, 1994), there have been studies exploring long term investment planning in the presence of future optionality and uncertainty. A real option is defined in the Green Book supplementary guidance as being 'an alternative or choice that becomes available through an investment opportunity or action'.

One of the principles of the FCERM-AG is that the appraisal process should be proportionate to the value of the investment decision. Whilst formal robust decision analysis and real options have been applied in research allied to significant FCERM decision problems, feedback from workshops during this study highlighted a tension between complex decision analysis and the costs that practitioners consider to be proportionate (noting that the latter is strongly influenced by the requirements, and budgets, set down by government agencies). One of the sources of this tension is the cost of the additional 
modelling required in order to evaluate multiple possible investment options under multiple future scenarios. There are also difficulties faced by practitioners in implementing realistic and flexible plans within appraisal calculations because of a lack of supporting tools and guidance. The analysis here therefore addresses this initial problem by offering a structured framework which enables the evaluation of flexible or adaptive plans, before moving on to more complex real options analysis.

\section{Characterising future uncertainties}

Of the many external factors that affect FCERM, three in particular were identified as relevant in most situations:

- $\quad$ climate change and its impacts (river flows, sea levels, waves);

- $\quad$ economic and population growth or decline;

- $\quad$ security and availability of funding for investments.

All three factors are largely outside of the control of the flood manager, and hence are referred to as 'autonomous', in the sense of 'all future developments which are not purposefully influenced by flood risk management measures and related policy instruments' (de Bruijn et al. 2008). Autonomous in this instance refers to external changes, not the separate concept of autonomous adaptation, which concerns adaptation that occurs without the need for deliberate intervention.

There could be a very wide range of uncertainty about each factor, and about the way in which changes might occur in combination between the factors. In this situation, it is useful to adopt a scenario analysis approach, where a number of alternative futures are created to be representative of future uncertainty.

Whilst scenario analysis has been used in FCERM (for example in the Foresight Future Flooding study, Defra (2004)) and specific guidance exists for some aspects of climate change scenarios, there is no common standard set of scenarios available to represent uncertainty over the multiple factors discussed above. Climate projections were used to inform a set of futures; further research and guidance is needed to properly represent the full range of alternative futures, specifically in relation to 
population and economic growth. Stakeholders considered that the development and provision of a suite of 'standardised futures' would be useful.

\section{Decision trees}

The market testing and consultation revealed a need for a simple and pragmatic method that could be applied to help quantify measures related to adaptive capacity. Decision trees were selected, given their common use in existing planning studies, and the ease with which they can be combined with analyses of multiple alternative futures. The decision tree sets out a structured view of the way in which future investment choices might unfold. It may not be feasible to capture all possible choices, and so the initial option development requires the range of choices to be narrowed down through the initial screening or short-listing into a manageable set of distinct options.

The project developed metrics for decisions where probabilistic information is available (e.g. climate change projections) and for decisions where probabilistic information is not available (e.g. population growth or economic development projections).

The following metrics are applicable whether or not the decision is being assessed using probabilistic futures:

- Flexibility: the number of future options that remain open following any investment choice (a measure of foreclosure).

- Robustness: the proportion of possible futures in which a given option has the highest performance.

- Opportunity loss: a measure of the potential benefits foreclosed by a choice, also known as regret, defined here by a comparison between the best outcome attainable from a chosen option and the best outcome attainable from any option (decision pathway).

For a choice between two options $A$ and $B$, the opportunity loss associated with option $A$ is $\mid \max (O A)-$ $\max (\mathrm{OA}, \mathrm{OB}) \mid$, where $\mathrm{OA}$ represents the set of outcomes that are available contingent on making choice A, expressed on an interval scale (e.g. NPV). 
When probabilities (subjective or derived from analysis) are available, it is possible to report a further metric:

- $\quad$ Expected performance: an average of the economic performance over all defined futures.

Feedback from stakeholders via the market testing workshop regarding the decision tree approach was largely positive, but practitioners found the construction of decision trees challenging. There are only a few published FCERM examples that users can learn from and further guidance was requested.

\section{Case study example}

A hypothetical case study was constructed, requiring the implementation of a flood alleviation scheme along a small reach of river in an English market town. Recent flooding has affected approximately 200 houses, shown in Figure B, and has highlighted the need for further investment in flood defence measures in this area. An initial screening phase identified three feasible options:

- Raising an existing wall on the south bank of the river to provide immediate protection for all but the largest floods.

- Installation of property level protection (PLP) as a relatively low cost measure offering partial reduction in damages.

- Construction of a bypass channel which is assumed to reduce flood risk to virtually nil. To explore future uncertainty, seven future scenarios are constructed - considering climate change, future development in the town and environmental constraints.

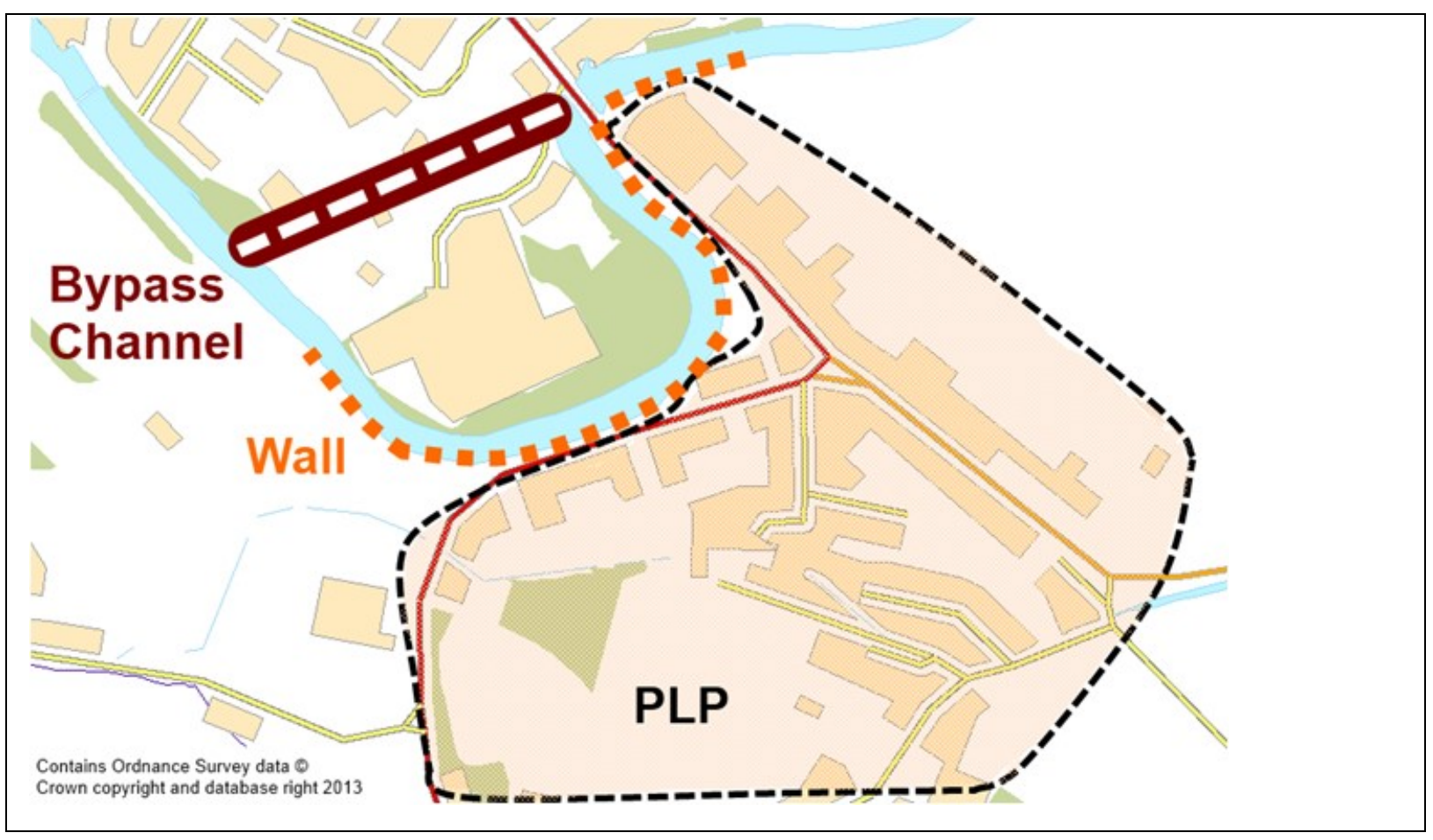

Figure B: Case study example map 
Seven autonomous futures are constructed, considering future uncertainty in climate change (assessed using a range of peak flow increases from Environment Agency, 2010c), economic development (assessed in terms of assumed change in economic value of assets in the floodplain) and environmental restrictions. It is assumed that each future could be weighted (equally in this case), but this is merely a basis to explore sensitivity to the weighting. The seventh future scenario represents a possible change in environmental legislation such that works within the river would suffer a penalty via increased costs. It is stressed that the data are hypothetical and developed for illustrative purposes, but are based upon existing hydraulic model outputs and real cost estimates.

Table A. Autonomous futures used as change scenarios in example decision tree analysis.

\begin{tabular}{|c|c|c|}
\hline $\begin{array}{c}\text { Future } \\
\text { scenario }\end{array}$ & Assumed climate change (EA, 2010c) & $\begin{array}{c}\text { Assumed change in } \\
\text { economic development }\end{array}$ \\
\hline 1 & Lower end & None \\
\hline 2 & Upper end & None \\
\hline 3 & Lower end & $+20 \%$ \\
\hline 4 & Upper end & $-20 \%$ \\
\hline 5 & Lower end & $-20 \%$ \\
\hline 6 & Upper end & $+20 \%$ \\
\hline $7^{*}$ & Upper end & $+20 \%$ \\
\hline
\end{tabular}

(Scenario $7^{*}$ is assumed the same as 4 but with additional constraints in river engineering works associated with postulated changes in environmental legislation).

A standard discounted cash flow analysis is assumed, as per HM Treasury Green Book guidance and the FCERM AG (the figures represent hypothetical NPV calculations). Benefits were defined as the risk avoided in terms of annual flood damages with respect to a baseline. This baseline represents the conditions that exist prior to the initial investment.

Climate change was modelled as a sequence of stepwise changes in flood damages for periods centred on 2025, 2055 and 2085, whilst the increase in economic risk due to development was assumed to occur linearly from 2008 (the initial investment) and stabilise at the value given in Table A (i.e. -20\% or $+20 \%$ ) by 2025 . The measures were used to form a decision tree consisting of four potential decision pathways (Figure D). The upper pathways in option A1 and A2 involve large upfront costs. These 
represent a precautionary approach, where investments are 'locked-in' early in the appraisal period.

The lower pathways in option B1 and B2 involve small upfront costs, but also smaller upfront benefits, and larger future costs and benefits. These represent a more adaptive approach, where larger investment would be deferred. Investment year is shown for each measure.

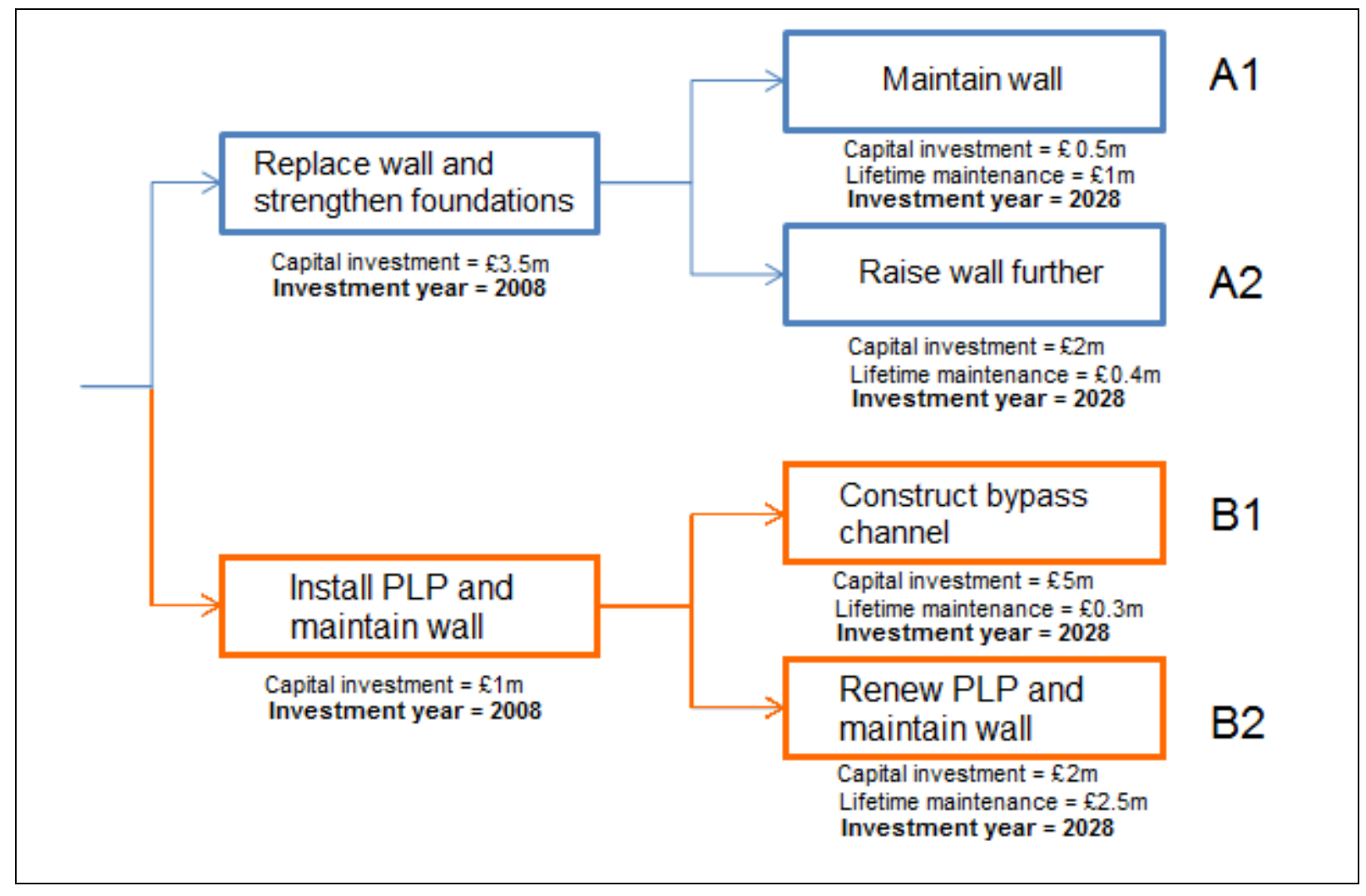

Figure C: Case Study Decision Tree

Table B presents the derived NPV (in millions of pounds) for each decision pathway under each future, as well as the expected performance. Values in bold represent the highest NPV that is predicted to occur under each future and across all decision pathways.

Table B Performance analysis for decision pathways in Figure D

\begin{tabular}{|c|c|c|c|c|c|c|c|c|}
\hline Future & $\mathbf{1}$ & $\mathbf{2}$ & $\mathbf{3}$ & $\mathbf{4}$ & $\mathbf{5}$ & $\mathbf{6}$ & $\mathbf{7}$ & \\
\hline Weight & $1 / 7$ & $1 / 7$ & $1 / 7$ & $1 / 7$ & $1 / 7$ & $1 / 7$ & $1 / 7$ & \\
\hline $\begin{array}{c}\text { Decision } \\
\text { pathway }\end{array}$ & & & & & & & & $\begin{array}{c}\text { Expected } \\
\text { performance } \\
\text { (NPV) }\end{array}$ \\
\hline A1 & $£ 14.36 \mathrm{~m}$ & $£ 13.00 \mathrm{~m}$ & $£ 17.16 \mathrm{~m}$ & $£ 15.53 \mathrm{~m}$ & $£ 11.56 \mathrm{~m}$ & $£ 10.48 \mathrm{~m}$ & $£ 14.51 \mathrm{~m}$ & $£ 13.80 \mathrm{~m}$ \\
\hline A2 & $£ 13.98 \mathrm{~m}$ & $£ 13.79 \mathrm{~m}$ & $£ 16.83 \mathrm{~m}$ & $£ 16.60 \mathrm{~m}$ & $£ 11.13 \mathrm{~m}$ & $£ 10.97 \mathrm{~m}$ & $£ 9.49 \mathrm{~m}$ & $£ 13.25 \mathrm{~m}$ \\
\hline B1 & $£ 14.43 \mathrm{~m}$ & $£ 13.88 \mathrm{~m}$ & $£ 17.22 \mathrm{~m}$ & $£ 16.56 \mathrm{~m}$ & $£ 11.64 \mathrm{~m}$ & $£ 11.19 \mathrm{~m}$ & $£ 15.37 \mathrm{~m}$ & $£ 14.33 \mathrm{~m}$ \\
\hline B2 & $£ 14.53 \mathrm{~m}$ & $£ 11.14 \mathrm{~m}$ & $£ 17.11 \mathrm{~m}$ & $£ 13.05 \mathrm{~m}$ & $£ 11.94 \mathrm{~m}$ & $£ 9.23 \mathrm{~m}$ & $£ 12.32 \mathrm{~m}$ & $£ 12.76 \mathrm{~m}$ \\
\hline
\end{tabular}


In this illustration, the flexibility measure is equal for all pathways and therefore not informative.

Option B produces the best performance in six out of the seven possible futures implying that it is robust to future uncertainties. Within option $B$, there are four futures under which B1 is anticipated to perform better than other decision pathways and two under which B2 would perform better. Hence making choice B now is robust because of this capacity to make a future choice between B1 and B2.

The opportunity loss, or regret, table for the initial options A and B is shown in Table C.

Table C Opportunity loss (regret) table, fm

\begin{tabular}{|l|r|r|r|r|r|r|r|}
\hline & \multicolumn{7}{|c|}{ Futures } \\
\hline Options & 1 & 2 & 3 & 4 & 5 & 6 & 7 \\
\hline A & 0.17 & 0.09 & 0.06 & 0.00 & 0.38 & 0.22 & 0.86 \\
\hline B & 0.00 & 0.00 & 0.00 & 0.04 & 0.00 & 0.00 & 0.00 \\
\hline
\end{tabular}

Should future 4 be realised, both of the decision pathways available in B would be out-performed by decision pathway $A 1$. The maximum regret from making the initial investment choice $B$ is therefore f0.04m (derived by subtracting the maximum value in branch $A$ under future $4, f 16.60 \mathrm{~m}$, from the maximum value in branch $B$ under future $4, f 16.56 \mathrm{~m}$ ). This small value reflects the understanding that option B is robust. If, instead, the initial investment option A was chosen, then the maximum regret would be $f 0.86 \mathrm{~m}$ (future 7). This is 20 times greater and further demonstrates the robustness of choosing to invest in B now.

Expected performance can be calculated as the average performance for each available decision pathway. In this case, the average NPV is used and the best outcome is $f 14.33 \mathrm{~m}$, corresponding to decision pathway B1 - one of the more adaptive of the investment pathways. Using a traditional NPV analysis alone, the expected performance of option A would be $f 13.53 \mathrm{~m}$ and for option B it would be f13.55m. There is little difference between these two figures, and on expected value alone it would be difficult to make an informed decision. However, it is clear from the consideration of robustness and opportunity loss above that option B is preferable.

Weightings associated with future scenarios can be ambiguous because of the lack of a comprehensive probabilistic framework for FCERM scenario generation. Considering sensitivity to any assumed 
weights is therefore a useful exercise. For example, stakeholder beliefs might consider stricter environmental legislation to be unlikely but may wish to check whether the analysis would change if the fourth future (in which option A performs best) is given greater weight. The implications of this can be tested by reducing the weight on the seventh future and redistributing it to the fourth future. This corresponds to asserting that the combination of high climate change, $+20 \%$ economic change and stricter environmental legislation is less plausible than the other futures, whilst low climate change and $+20 \%$ economic change is more plausible. The result of this test is that the expected performance of option A increases to $f 14.16 \mathrm{~m}$ whilst option B becomes $f 13.96 \mathrm{~m}$. However, robustness and opportunity loss are not derived from an analysis of weights and these metrics remain unchanged. Arguably the choice between options A and B remains finely balanced on grounds of NPV alone, but leans towards B on the basis of the non-probabilistic analysis.

In general, investing now in decision B requires relatively low 'locked-in' costs and, most importantly, will delay making difficult decisions until a future time period. By doing so, adaptability is embedded into the decision-making process and future uncertainty is managed by waiting until better information becomes available. The choice of option B is further supported via the use of additional performance metrics, ensuring that a potentially difficult decision can be more robustly justified than if solely using a NPV analysis.

Evaluating the business case for a flexible investment plan - taking the analysis further

While the decision tree analysis provides some measure of the potential benefits gained by leaving future investment choices open, a more detailed analysis can be achieved through assessing the economic case using real options analysis concepts. This alternative or choice (such as the option to abandon an investment if future climate change is not as originally anticipated) has an inherent value associated with it, termed the option value. The real options approach extends the type of decision tree analysis discussed above by introducing a decision rule, such that future investment choices are conditional on the futures used to represent future uncertainty. This means that the costs and benefits of investment in the future are assessed under the assumption that a decision-maker will adapt rationally to future change. 
An additional hypothetical case study was used to explore how real options analysis could be applied.

The study demonstrated the sensitivity of two archetypical flood risk management decisions to uncertainty both in future river flows and to socio-economic change. In the first, the case of a flood defence that can be with a widened base was considered, providing the option to heighten it at a later date, or alternatively it could be built to a fixed height with no further options apart from costly reconstruction. In a second case, a portion of undeveloped, flood-prone land separated an existing development from the river. A decision could be made to purchase the land and forgo development. A real options analysis was used to identify the circumstances in which it would be cost-beneficial to purchase the land, which depends on the value of existing assets exposed to flooding and how that value would change were development to take place.

\section{Final conclusions, recommendations $\&$ areas for further research}

\section{Conclusions and practical relevance}

Understanding and managing future uncertainty in FCERM is complex and therefore developing the approaches to assess the value of responses to such uncertainty requires a clear, structured approach. The development of the supplementary appraisal guide represents significant progress in providing approaches which assist decision-makers and practitioners in developing and appraising managed adaptive approaches for FCERM. The guide supplements existing appraisal guidance in England provided by the Treasury, Defra and the Environment Agency and, overall, improves the ability to managed adaptive approaches. This is achieved by providing clear guidance on where there is a need to fully value adaptive approaches, offering a measured step forward in illustrating how strategies can be expressed as decision trees and facilitating the development of multiple futures and identifying situations where climate uncertainties can be given probability weightings based on (arguably) objective science and also deep uncertainties where this may be inappropriate.

\section{Areas for further work}

There remains a need for the ongoing evolution of guidance, building on future research and practical experience. Specifically, further work is required in relation to three areas. First, the construction of decision trees in order to assist with the appraisal of more complex decision structures as the examples 
available in published research are limited. Second, the development of a set of prepared benefit estimates or multipliers linked to 'standard' autonomous futures so as to provide a consistent treatment of uncertainty. Finally, linking to the need for a wider change in mind-set amongst decisionmakers to increase the adoption of adaptive approaches there is a potential need for FCERM funding arrangements in England to provide incentives for adaptability via target outcomes regarding the types of solutions favoured. 


\section{Acknowledgements}

This case study is based on project SC110001 'Accounting for adaptive capacity in FCERM options appraisal' commissioned as part of the joint Environment Agency/Defra Flood and Coastal Erosion Risk Management Research and Development Programme. The project was led by JBA Consulting; the wider consortium of partners included Professor Jim Hall, Paul Sayers, Professor Zoran Kapelan, University of Exeter and Royal Haskoning DHV.

\section{References}

Committee on Climate Change (2012) Climate change - is the UK preparing for flooding and water scarcity? Adaptation Sub-Committee Progress Report. Available at: http://www.theccc.org.uk/publication/climate-change-is-the-uk-preparing-for-flooding-and-waterscarcity-3rd-progress-report-2012/ (accessed 1 August 2012).

de Bruijn et al. (2008) Long term planning - robust strategic decision making in the face of gross uncertainty: tools and application to the Thames. Floodsite Task 14, Report T14-08-01. Available at: http://www.floodsite.net/html/partner_area/project_docs/T14_08_01_FRM_Strategies_D14_1_V3_ 5_P46.pdf (accessed March 2013).

DCLG (2012a) National Planning Policy Framework. Department for Communities and Local Government. Available at:

http://www.communities.gov.uk/planningandbuilding/planningsystem/planningpolicy/ planningpolicyframework/ (accessed 10 August 2012).

Defra (1999) Flood and coastal defence project appraisal guidance: economic appraisal - FCDPAG3. Available at: 
http://archive.defra.gov.uk/environment/flooding/documents/policy/guidance/fcdpag/fcdpag3.pdf (accessed 10 August 2012).

Defra (2004) Foresight Future Flooding. Available at:

https://www.gov.uk/government/publications/future-flooding (accessed 1 August 2012)

Defra (2005) Making space for water. Available at:

http://archive.defra.gov.uk/environment/flooding/documents/policy/strategy/strategy-

response1.pdf (accessed 1 August 2012).

Defra (2006) Flood and coastal defence appraisal guidance - FCDPAG3 economic appraisal supplementary note to operating authorities - climate change impacts. Available at:

http://archive.defra.gov.uk/environment/flooding/documents/policy/guidance/fcdpag/fcd3climate. pdf (accessed 1 August 2012).

Defra (2009a) Appraisal of flood and coastal erosion risk management - a Defra policy statement. Available at: http://www.defra.gov.uk/publications/files/pb13278-erosion-manage-090619.pdf (accessed 1 August 2012).

Defra (2009b) The appraisal of adaptation options in Flood and Coastal Erosion Risk Management FD2617. Available at: http://evidence.environment-

agency.gov.uk/FCERM/en/Default/HomeAndLeisure/Floods/WhatWereDoing/IntoTheFuture/Scienc eProgramme/ResearchAndDevelopment/FCRM/Project.aspx?ProjectID=f4394a7b-5e9d-4572-88feb443f5af9888\&PagelD=424af8b1-26e4-446d-bc67-ce3a0952947b (accessed March 2012 and 18 January 2013).

Defra (2009c) UK climate projections (UKCP09). Available at:

http://ukclimateprojections.defra.gov.uk/21678 (accessed 1 August 2012). 
Defra (2010) Surface water management plan guidance. Available at:

http://www.defra.gov.uk/publications/files/pb13546-swmp-guidance-100319.pdf (accessed 10 August 2012).

Defra (2011a) Practicalities for implementing regionalised allowances for climate change on flood flows, Final Technical Report - Defra Project FD2648. Available at:

http://randd.defra.gov.uk/Document.aspx?Document=20110608FD2648_final_results_v3.pdf (accessed April 2013).

Defra (2011b) Shoreline management plan guidance. Available at:

http://www.defra.gov.uk/publications/2011/06/10/pb11726-shoreline-guidance/ (accessed 10 August 2012).

Defra (2011c) Future water: The government's water strategy for England. Available at:

https://www.gov.uk/government/publications/future-water-the-government-s-water-strategy-forengland (accessed 10 August 2012)

Defra (2012) UK Climate Change Risk Assessment: Government Report. Available at: https://www.gov.uk/government/uploads/system/uploads/attachment data/file/69487/pb13698climate-risk-assessment.pdf (Accessed August 2012)

Dixit, A.K. and Pindyck, R.S. (1994) Investment under uncertainty. Princeton University Press.

Environment Agency (2004) Catchment Flood Management Plans: Volume 1 Policy Guidance. Available at:

http://www.staffsmoorlands.gov.uk/sites/default/files/documents/pages/EA Catchment Flood Ma nagement Plans.pdf (accessed 1 August 2012) 
Environment Agency (2009) Investing for the future - flood and coastal risk management in England: a long-term investment strategy. Available at: http://publications.environmentagency.gov.uk/PDF/GEHO0609BQDF-E-E.pdf (accessed 1 August 2012).

Environment Agency (2010a) Flood and Coastal Erosion Risk Management appraisal guidance (FCERM-AG). Available at: http://www.environment-agency.gov.uk/research/planning/116707.aspx (accessed 1 August 2012).

Environment Agency (2010b) FCERM AG supporting guidance for appraisal summary tables. Available at: http://a0768b4a8a31e106d8b050dc802554eb38a24458b98ff72d550b.r19.cf3.rackcdn.com/geho0310bsdd-e-e.pdf (accessed 10 October 2012).

Environment Agency (2010c) Adapting to climate change: advice for flood and coastal erosion risk management authorities. Available at: http://publications.environmentagency.gov.uk/PDF/GEHO0711BTZU-E-E.pdf (accessed 10 August 2012). Environment Agency (2011) Understanding the risks, empowering communities, building resilience: the national Flood and Coastal Erosion Risk Management Strategy for England. Available at: http://www.official-documents.gov.uk/document/other/9780108510366/9780108510366.pdf (accessed 1 August 2012).

Environment Agency (2012a) FCRM asset mangement: maintenance standards. Enviroment Agency, Bristol.

Environment Agency (2012b) Principles for implementing flood and coastal resilience funding partnerships. Available at: http://publications.environment-agency.gov.uk/PDF/GEHO0312BWDK-EE.pdf (accessed 5 July 2012). 
Environment Agency (2012c) TE2100 Plan. Available at: http://a0768b4a8a31e106d8b050dc802554eb38a24458b98ff72d550b.r19.cf3.rackcdn.com/LIT7540_43858f.pdf. (accessed 10 August 2012).

FLOODsite Consortium (2009) Integrated flood risk analysis and management methodologies. Available at: http://www.floodsite.net/.

HM Treasury (2003) The Green Book: appraisal and evaluation in central government. Available at: http://www.hm-treasury.gov.uk/d/green_book_complete.pdf (accessed 1 August 2012).

HM Treasury/Defra (2009) Accounting for the effects of climate change - supplementary Green Book guidance. Available at: http://archive.defra.gov.uk/environment/climate/documents/adaptationguidance.pdf (accessed 1 August 2012).

J.L. Cochrane and M. Zeleny (1973) Multiple Criteria Decision Making. University of South Carolina Press, Columbia, 1973

P. LINQUITI and N. VONORTAS, (2012) the value of flexibility in adapting to climate change: a real options analysis of investments in coastal defense, Clim. Change Econ. 03, 1250008 DOI: $10.1142 / \mathrm{S} 201000781250008 \mathrm{X}$ Mathews and Salmon (2007) Valuing risky projects with high returns. Tutorials in Operations Research. http://www.iriweb.org/Public Site/RTM/Volume 52 Year 2009/SeptemberOctober2009RTM/Valuing Risky Projects with Real Options.aspx

Sayers, P., Galloway, G. and Hall, J. (2012) Robust decision making under uncertainty - towards adaptive and resilient flood risk management infrastructure. In: P. Sayers (ed.) Flood risk: design, management and planning of flood defence infrastructure. Thomas Telford. 
UK CIP (Climate Impacts Programme) (undated) Identifying adaptation options. Available at: http://www.ukcip.org.uk/wordpress/wp-content/PDFs/ID_Adapt_options.pdf (accessed 21 December 2012).

Woodward, M., Goudlby, B., Kapelan, Z., Khu, S.-T. and Townend, I. (2011) Real options in flood risk management decision making. Journal of Flood Risk Management, 4(4), 339-349. 